\title{
On Service Efficiency of Public Traditional Chinese Medicine (TCM) Hospitals of Hubei Province in 2017
}

\author{
YANG Ke ${ }^{1}$, SHUAI Li-na ${ }^{1}, \mathrm{LI} \mathrm{Na}^{1}, \mathrm{CHEN} \mathrm{Li}^{1}{ }^{*}$ \\ ${ }^{1}$ School of Management, Hubei University of Chinese Medicine, Wuhan, 430065
}

\begin{abstract}
In order to put forward policy suggestions for improving the service efficiency of public TCM hospitals in Hubei Province, the statistics of 94 public TCM hospitals of Hubei Province in 2017 was collected by using the comprehensive statistical management information system of TCM there, and the service efficiency of TCM hospitals was analyzed with the DEA-BCC model. The research showed, in 2017, the average technical efficiency, pure technical efficiency and scale efficiency of public TCM hospitals in Hubei Province were $0.919,0.939$ and 0.979 respectively. There were $27.7 \%$ of hospitals with effective DEA, 39.4\% with effective pure technical efficiency, $31.9 \%$ with effective scale efficiency, and $61.7 \%$ of public TCM hospitals with diminishing returns to scale. The pure technical efficiency is an important factor restricting the effective DEA of TCM hospitals in Hubei Province, and the scale efficiency also has to be improved. The service efficiency of grade II hospitals of TCM are better than that of grade III, and hospitals in central regions are better than that of eastern and western regions. Therefore, local hospitals should take tailored reforms to improve service efficiency according to local conditions.
\end{abstract}

\section{Introduction}

As the treasure of ancient Chinese science, TCM is an important part of China's health service. In recent years, Hubei Province is committed to building a powerful province of TCM and promoting the revitalization and development of TCM, among which the improvement of the TCM service system has always been the focus of work. As an important undertaker of TCM service, public TCM hospitals' service ability and efficiency are directly related to the overall effectiveness of the TCM service system. This study analyzed the operational efficiency of public TCM hospitals of Hubei Province in 2017 with the Data Envelopment Analysis (DEA) method and provided a decision-making basis for improving the operational efficiency of hospitals.

\section{Materials and Methods}

\subsection{Sources}

Statistics of 94 public TCM hospitals of and above grade II in 2017 was collected by using the comprehensive statistical management information system of TCM in Hubei Province.

Based on the geographical location, the eastern region of Hubei Province includes cities of Huangshi, Huanggang and Xianning, the central region includes Wuhan, Tianmen, Xiantao, Qianjiang, Jingmen, Xiaogan, Suizhou and Ezhou, and the western region includes Shiyan, Yichang, Xiangyang, Jingzhou, Enshi and the
Shennongjia forest region ${ }^{[1]}$. 20, 32 and 42 public TCM hospitals in the eastern, central and western parts of Hubei Province respectively were included in this study.

\subsection{Research Methods}

\subsubsection{DEA Model}

The data envelopment analysis (DEA) is a nonparametric efficiency analysis method, which is used to evaluate the relative effectiveness of decision-making units with multiple inputs and outputs. It has been widely used in the efficiency evaluation of enterprises and public sectors ${ }^{[2-4]}$. Under the assumption of variable return to scale (VRS), the technical efficiency (TE) of each decision unit can be obtained by using the BCC model, and further decomposed into pure technical efficiency (PTE) and scale efficiency (SE) ${ }^{[5]}$, TE $=$ PTE $\times \mathrm{SE}$. The value of each index is in the range of $0 \sim 1$. The higher the value, the more efficient it is.

\subsubsection{Statistical Analysis}

The excel was used to establish the database, in which the relevant statistics of public TCM hospitals of Hubei Province in 2017 were imputed, then performing the descriptive statistical analysis, and DEA with DEAP2.1.

\footnotetext{
${ }^{*}$ Corresponding author: Chen Li, E-mail address: chenli0401@163.com
} 


\section{Result}

\subsection{Description of Input and Output Indicators}

Input and output indicators were selected through expert consultation and literature research and by combining with the existing data. The total person-times of medical visits, the number of discharged patients, medical income and the average length of stay were selected as output indicators, while the number of available beds, the number of on-the-job employees, the hospital building area and the cost of medical service as input indicators. The indicators are shown in Table 1.

Table 1. 2017 statistics of indicators of public TCM in Hubei Province

\begin{tabular}{|l|c|c|c|c|c|}
\hline & Minimum & Lower quartile & Median & Upper quartile & Maximum \\
\hline Medical visits & 20,216 & 90,436 & 150,959 & $273,151.75$ & $2,720,264$ \\
\hline Number of discharges & 13 & $6,901.75$ & $12,612.5$ & $18,442.5$ & 85,883 \\
\hline Average length of stay & 5.2 & 8.375 & 9.6 & 11.1 & 27.7 \\
\hline $\begin{array}{l}\text { Medical income (thousand } \\
\text { RMB) }\end{array}$ & 5,220 & $40,747.5$ & 83,655 & $142,292.5$ & $1,869,480$ \\
\hline Number of available beds & 30 & 227.5 & 385.9 & 573.325 & $2,430.8$ \\
\hline $\begin{array}{l}\text { Number of health staff on } \\
\text { duty }\end{array}$ & 68 & 239 & 377.5 & 565.25 & 2,875 \\
\hline Hospital building area & 3,348 & $9,586.5$ & 17,847 & 29,559 & 333,256 \\
\hline $\begin{array}{l}\text { Medical cost } \\
\text { thousand RMB) }\end{array}$ & 6,350 & 40,000 & 74,970 & 125,145 & $1,681,610$ \\
\hline
\end{tabular}

In 2017, there were 94 public TCM hospitals of and above grade II in Hubei Province, including 25 grade III hospitals and 69 grade II hospitals. It can be seen from the above table that there are great differences between the input of human, financial and material resources and the output of medical service among these hospitals.

\subsection{DEA Results of Hospital Service Efficiency}

On the whole, in 2017, the average technical efficiency, pure technical efficiency and scale efficiency of public TCM hospitals in Hubei Province were 0.919, 0.939 and 0.979 respectively. The operation efficiency of TCM hospitals at different grades in different regions is shown in Table 2 .

Table 2. 2017 Average efficiency of public TCM hospitals in Hubei Province

\begin{tabular}{|c|c|c|c|c|c|c|}
\hline & \multicolumn{2}{|c|}{$\begin{array}{c}\text { Technical } \\
\text { efficiency }\end{array}$} & \multicolumn{2}{c|}{$\begin{array}{c}\text { Pure technical } \\
\text { efficiency }\end{array}$} & \multicolumn{2}{c|}{$\begin{array}{c}\text { Scale } \\
\text { efficiency }\end{array}$} \\
\cline { 2 - 7 } & $\begin{array}{c}\text { Grade } \\
\text { II }\end{array}$ & $\begin{array}{c}\text { Grade } \\
\text { III }\end{array}$ & Grade II & Grade III & $\begin{array}{c}\text { Grade } \\
\text { II }\end{array}$ & $\begin{array}{c}\text { Grade } \\
\text { III }\end{array}$ \\
\hline $\begin{array}{c}\text { Eastern } \\
\text { region }\end{array}$ & 0.911 & 0.781 & 0.928 & 0.809 & 0.982 & 0.967 \\
\hline $\begin{array}{c}\text { Central } \\
\text { region }\end{array}$ & 0.953 & 0.919 & 0.959 & 0.957 & 0.993 & 0.961 \\
\hline $\begin{array}{c}\text { Western } \\
\text { region }\end{array}$ & 0.916 & 0.922 & 0.934 & 0.957 & 0.981 & 0.963 \\
\hline
\end{tabular}

Based on the geographical location, the technical efficiency, pure technical efficiency and scale efficiency of TCM hospitals in central China were much better than those in eastern and western China. In addition, the efficiency of grade II hospitals was mostly better than that of grade III hospitals. The specific analysis is as follows.

\subsubsection{Analysis of Technical Efficiency}

In 2017, the average technical efficiency of public TCM hospitals in Hubei Province was 0.919, and 26 hospitals achieved effective DEA, accounting for $27.7 \%$. Hospitals with technical efficiency of $0.9 \sim 1,0.8 \sim 0.9$ and below 0.8 accounted for $35.1 \%, 29.8 \%$ and $7.5 \%$ respectively. A total of 5 grade III hospitals and 21 grade II hospitals achieved effective DEA, and the distribution in each region is shown in Table 3.

Table 3. 2017 DEA effectiveness of public TCM hospitals in Hubei Province

\begin{tabular}{|c|c|c|c|c|c|c|}
\hline \multirow{2}{*}{} & $\begin{array}{c}\text { Number of } \\
\text { hospitals } \\
\text { with effective } \\
\text { DEA }\end{array}$ & \multicolumn{2}{|c|}{$\begin{array}{c}\text { Number of } \\
\text { hospitals } \\
\text { with non-effective } \\
\text { DEA }\end{array}$} & \multicolumn{2}{|c|}{$\begin{array}{c}\text { Effectiveness } \\
\text { ratio }\end{array}$} \\
\cline { 2 - 7 } & $\begin{array}{c}\text { Grade } \\
\text { II }\end{array}$ & $\begin{array}{c}\text { Grade } \\
\text { III }\end{array}$ & $\begin{array}{c}\text { Grade } \\
\text { II }\end{array}$ & $\begin{array}{c}\text { Grade } \\
\text { III }\end{array}$ & $\begin{array}{c}\text { Grade } \\
\text { II }\end{array}$ & $\begin{array}{c}\text { Grade } \\
\text { III }\end{array}$ \\
\hline $\begin{array}{c}\text { Eastern } \\
\text { region }\end{array}$ & 1 & 0 & 16 & 3 & $5.89 \%$ & $0.00 \%$ \\
\hline $\begin{array}{c}\text { Central } \\
\text { region }\end{array}$ & 11 & 2 & 8 & 11 & $\begin{array}{c}57.90 \\
\%\end{array}$ & $\begin{array}{c}15.38 \\
\%\end{array}$ \\
\hline $\begin{array}{c}\text { Western } \\
\text { region }\end{array}$ & 9 & 3 & 24 & 6 & $\begin{array}{c}27.27 \\
\%\end{array}$ & 33.33 \\
$\%$
\end{tabular}

From the perspective of DEA efficiency, the proportion of grade II hospitals in the central region was higher than that in other regions, reaching $57.90 \%$. While in the eastern region, no grade III hospital 
achieved effective DEA; from the average efficiency, grade II hospitals in the central region were the highest, reaching 0.953 . And except for grade III hospitals in the eastern region (0.781), all grades of TCM hospitals in other regions were higher than 0.9. By analyzing the DEA efficiency of TCM hospitals from the hospital grade and geographical region, it was found that there was no significant difference in DEA efficiency between grade II and grade III hospitals $\left(\chi^{2}=0.999, \mathrm{P}=0.318>\right.$ $0.05)$. But there was a significant difference in DEA efficiency among eastern, central and western hospitals $\left(\chi^{2}=7.838, \mathrm{P}=0.020<0.05\right)$.

\subsubsection{Analysis of Pure Technical Efficiency}

The average pure technical efficiency of 94 public TCM hospitals was 0.939 , and 37 hospitals achieved pure technical efficiency, accounting for $39.4 \%$. The hospitals with pure technical efficiency of $0.9 \sim 1,0.8 \sim 0.9$ and below 0.8 accounted for $33.0 \%, 24.5 \%$ and $4.3 \%$ respectively. There were 28 grade $\|$ hospitals and 9 grade III hospitals that achieved effective pure technical efficiency, among which distributed in the eastern, central and western regions are 3,17 and 17 respectively. These hospitals achieved the largest output under the current input, while the other 57 hospitals still had problems of redundant input or insufficient output. Through the analysis of the average efficiency of TCM hospitals at all grades in different regions, it was found that the pure technical efficiency was better than the technical efficiency. The average pure technical efficiency of all hospitals in the central and grade III hospitals in the western was higher than 0.95 . And the average pure technical efficiency of grade III hospitals in the eastern was the lowest, which was 0.809. 11 TCM hospitals were technically effective, but with noneffective DEA, including 7 grade II hospitals and 4 grade III hospitals. For these hospitals, health resources have been fully utilized, but DEA is ineffective due to the lack of effective scale. By chi-square test, it was found that there was no significant difference in the pure technical efficiency of hospitals of different grades $\left(\chi^{2}=\right.$ $0.161, \mathrm{P}=0.688>0.05)$, but there was significant difference in the pure technical efficiency of hospitals in different regions $\left(\chi^{2}=7.535, \mathrm{P}=0.023<0.05\right)$.

\subsubsection{Analysis of Scale Efficiency}

In 2017, the average scale efficiency of public TCM hospitals in Hubei Province was 0.979 , with 30 hospitals achieving scale efficiency, accounting for $31.9 \%$. Hospitals with scale efficiency of $0.9 \sim 1$ and $0.8 \sim 0.9$ accounted for $63.8 \%$ and $4.3 \%$ respectively. There were 24 grade II hospitals, 6 grade III hospitals that achieved effective scale efficiency, among which distributed in the eastern, central, and western regions were 3,15 , and 12 respectively. The scale of these hospitals was appropriate, and the growth of output factors matched the growth of input factors. The average scale efficiency of TCM hospitals of different grades in different regions were greater than 0.95 , and the average scale efficiency of grade $\|$ hospitals in the central region was the most prominent, reaching 0.993. It was found that there was no significant difference in the scale efficiency of hospitals of different grades $\left(\chi^{2}=0.982, \mathrm{P}=0.322>\right.$ 0.05 ). While there was significant difference in the scale efficiency of hospitals among eastern, central and western regions $\left(\chi^{2}=6.145, \mathrm{P}=0.046<0.05\right)$. In general, scale efficiency $>$ pure technical efficiency $>$ technical efficiency, which means that to achieve DEA efficiency, it is more important to optimize the input-output structure and promote pure technical efficiency, compared with adjusting hospital development scale and improving scale efficiency.

\subsubsection{Analysis of Returns to Scale}

By analyzing the returns to scale of TCM hospitals, the number of hospitals with increasing, decreasing and unchanged returns to scale were 6,58 and 30 respectively. The situation of different levels and regions is shown in Table 4.

Table 4. 2017 statistics of returns to scale of public TCM hospitals in Hubei Province

\begin{tabular}{|c|c|c|c|c|c|c|}
\hline & \multicolumn{2}{|c|}{$\begin{array}{c}\text { Increasing } \\
\text { returns to scale }\end{array}$} & \multicolumn{2}{c|}{$\begin{array}{c}\text { Decreasing } \\
\text { returns to scale }\end{array}$} & \multicolumn{2}{c|}{$\begin{array}{c}\text { Unchanged } \\
\text { returns to scale }\end{array}$} \\
\cline { 2 - 7 } & $\begin{array}{c}\text { Grade } \\
\text { II }\end{array}$ & $\begin{array}{c}\text { Grade } \\
\text { III }\end{array}$ & $\begin{array}{c}\text { Grade } \\
\text { II }\end{array}$ & $\begin{array}{c}\text { Grade } \\
\text { III }\end{array}$ & $\begin{array}{c}\text { Grade } \\
\text { II }\end{array}$ & $\begin{array}{c}\text { Grade } \\
\text { III }\end{array}$ \\
\hline $\begin{array}{c}\text { Eastern } \\
\text { region }\end{array}$ & 0 & 0 & 14 & 3 & 3 & 0 \\
\hline $\begin{array}{c}\text { Central } \\
\text { region }\end{array}$ & 2 & 1 & 5 & 9 & 12 & 3 \\
\hline $\begin{array}{c}\text { Western } \\
\text { region }\end{array}$ & 1 & 2 & 23 & 4 & 9 & 3 \\
\hline
\end{tabular}

In 2017, $61.7 \%$ of public TCM hospitals in Hubei Province showed decreasing returns to scale, that is, the growth of input factors was higher than that of output factors, and the marginal income decreased with the expansion of scale. $60.9 \%$ of grade II hospitals and $64.0 \%$ of the grade III hospitals had diminishing returns to scale, accounting for $85.0 \%, 43.8 \%$ and $64.3 \%$ respectively in the eastern, central and western regions. The problem of the over-large operation of TCM hospitals in the eastern region was more serious. The returns to scale of $6.38 \%$ TCM hospitals was increasing, accounting for $4.4 \%$ and $12.0 \%$ of grade II and grade III hospitals respectively, and $0.0 \%, 9.4 \%$ and $7.1 \%$ of the eastern, central and western regions respectively. These hospitals have not yet reached the optimal scale. Based on the analysis of hospitals with unchanged returns to scale, it was found that $63.2 \%$ of grade II hospitals in the central region achieved scale efficiency, which was much higher than that in other regions. However, the proportion of grade III hospitals in the eastern region 
was 0 , which showed that there was a large gap between the regions.

\subsection{Slack Variable Analysis of Non-effective DEA TCM Hospital}

By analyzing the input and output slack variables, the basis for optimizing the input-output structure can be

Table 5. 2017 input and output slack variables of medical resources of TCM hospitals in Hubei Province

\begin{tabular}{|c|c|c|c|c|c|c|c|c|}
\hline & $\mathrm{S}^{1-}$ & $\mathrm{S}^{2-}$ & $\mathrm{S}^{3-}$ & $\mathrm{S}^{4-}$ & $\mathrm{S}^{1+}$ & $\mathrm{S}^{2+}$ & $\mathrm{S}^{3+}$ & $\mathrm{S}^{4+}$ \\
\hline 1 & 0.00 & 0.00 & 0.00 & 0.00 & 0.00 & 0.00 & 0.00 & 0.00 \\
\hline 2 & 0.00 & 35.84 & $10,125.49$ & 0.00 & $442,965.61$ & $4,203.51$ & 0.00 & 0.00 \\
\hline 3 & 0.00 & 0.00 & 0.00 & 0.00 & 0.00 & 0.00 & 0.00 & 0.00 \\
\hline 4 & 0.00 & 0.00 & 0.00 & 0.00 & 0.00 & 0.00 & 0.00 & 0.00 \\
\hline 5 & 0.00 & 88.99 & 0.00 & $3,117.48$ & 0.00 & 0.00 & 0.00 & 0.00 \\
\hline$\ldots$ & $\ldots$ & $\ldots$ & $\ldots$ & $\ldots$ & $\ldots$ & $\ldots$ & $\ldots$ & $\cdots$ \\
\hline 90 & 0.00 & 10.34 & 0.00 & 0.00 & $30,087.06$ & 0.00 & 0.00 & 0.00 \\
\hline 91 & 0.00 & 31.34 & $12,373.71$ & 0.00 & $28,031.29$ & $3,989.04$ & 0.00 & 0.00 \\
\hline 92 & 0.00 & 0.00 & 0.00 & 0.00 & 0.00 & 0.00 & 0.00 & 0.00 \\
\hline 93 & 0.00 & 52.98 & 0.00 & 0.00 & $15,116.56$ & 615.15 & 0.00 & 0.00 \\
\hline 94 & 0.00 & 0.00 & 0.00 & 0.00 & 0.00 & 0.00 & 0.00 & 0.00 \\
\hline
\end{tabular}

Note: S1-, S2-, S3- and S4- represent the slack variables of the number of available beds, of the number of on-the-job employees, of the hospital building area, and of medical costs respectively. S1+, S2+, S3+ and S4+ represent the slack variables of the total person-times of medical visits, of the number of discharges, of the average length of stay and of the medical income.

If DEA is effective in all 94 TCM hospitals, 676 beds, 1,604 on-the-job staff, $158,846.09$ square meters of hospital building area, medical costs by 31.1748 million yuan would be reduced, and 2,122,752 person-times of medical visits, 30,574 person-times of discharges and the average length of stay by 0.01 day be increased.

This paper analyzes the slack variables of input and output of hospitals at different grades in different regions. In terms of input indicators, generally, under the current output level, TCM hospitals at all grades in all regions have input redundancy. The input redundancy of grade III hospitals of TCM was higher than that of grade II, and the input redundancy of TCM hospitals in the eastern region was higher than that of central and western regions. Among the four input factors selected, the number of on-the-job staff and the area of hospital building were the most redundant, especially in grade III hospitals of TCM in the eastern region, with the average redundancy rates of $21.54 \%$ and $14.06 \%$ respectively. According to the analysis of the output indicators, when the input factors were fully utilized, the average growth rate of medical visits in grade II hospitals of TCM in the eastern, central and western regions was $10.90 \%$, $10.11 \%$ and $5.51 \%$ respectively, and in grade III hospitals was $13.92 \%, 12.69 \%$ and $2.65 \%$ respectively. Hospitals in the eastern and central regions can be improved more in medical visits than those in the western regions. Analyzing the person-times of discharges, the average growth rate of grade II hospitals of TCM in the eastern, central and western regions was $0.20 \%, 0.58 \%$ and $0.58 \%$ respectively, and grade III was
$1.25 \%, 3.94 \%$ and $2.97 \%$ respectively. Compared with grade II hospitals, the inpatient services of grade III hospitals in the central and western regions could be further improved.

\section{Discussions}

\subsection{The pure technical efficiency being an important factor that restricts the DEA efficiency of TCM hospitals in Hubei Province, and the scale efficiency also being necessary to be improved}

In 2017, the average of technical efficiency, pure technical efficiency and scale efficiency of public TCM hospitals in Hubei Province was 0.919, 0.939 and 0.979 respectively, and the average of pure technical efficiency was lower than that of scale efficiency. This problem was common in hospitals at all grades in all regions, and pure technical efficiency was more significant for the realization of effective DEA. Based on this, local TCM hospitals can promote both the management level and medical technology by learning advanced management theory, improving management ability, optimizing workflow, reforming performance appraisal systems, strengthening the training of staff, and building medical disciplines embodied excellent effect of TCM treatment ${ }^{[6-7]}$. Additionally, the pure technical efficiency should be improved, the input redundancy or insufficient output be alleviated, and the input-output structure be optimized. 
On the whole, the scale efficiency was better than the pure technical efficiency, but only $31.9 \%$ of hospitals achieved scale efficiency. And $61.7 \%$ of hospitals had diminishing returns to scale, even with problems of overlarge operation scale and input growth ratio being greater than that of output. Health administrative departments should make reasonable strategies for the development scale of TCM hospitals at all grades. And hospitals themselves should also change the past development ideas of expanding the hospital building area and purchasing high-end types of equipment, and pay attention to the efficient use of existing resources, or reduce the scale of individual hospitals by building branch hospitals ${ }^{[8]}$.

In 2016, under the leadership of Hubei Provincial Hospital of TCM, the TCM Alliance of Hubei Province was established. And in 2017, the Hubei Provincial Hospital of TCM Group was build. With the help of existing platforms, it can actively promote the cooperation of TCM hospitals in talent cultivation, scientific research, specialty construction, and TCM preparations'research, development and promotion. What's more, under the overall goal of building a strong province of TCM, it can promote the scientific allocation of hospitals'human, equipment, finance and other resources in the whole province, thus realizing the coordinated development of production, teaching and research of TCM and the improvement in the service efficiency of TCM hospitals.

\subsection{The service efficiency of grade II hospitals of TCM being better than that of grade III}

In 2017, the average values of technical efficiency, pure technical efficiency and scale efficiency of grade II hospitals of TCM in Hubei Province were 0.925, 0.939 and 0.985 respectively, and those of grade III were 0.904 , 0.939 and 0.962 respectively. Overall, the efficiency of grade II hospitals was better than that of grade III. The hospital service efficiency was not necessarily directly related to the hospital grade, which was consistent with the research conclusion of Pang Zhenmiao et al..$^{[9]}$. Further analysis showed that the average pure technical efficiency of the two grades of hospitals was the same, and the lower technical efficiency of grade III hospitals was affected by scale efficiency. $64.0 \%$ of grade III hospitals had diminishing returns to scale and over-large operation scale. It is suggested that grade III hospitals should decrease unnecessary medical and health resource investment. In addition, they should reasonably guide patients with basic diseases, common diseases and chronic diseases to grassroots medical institutions through the implementation of the hierarchical medical treatment system and the two-way referral system, which is helpful for promoting the sound development of TCM hospitals at all grades, curbing the continuous and disorderly expansion of grade III hospitals, and better undertaking responsibilities in the medical and health system.

\subsection{The service efficiency of TCM hospitals in the central region being better than that in the eastern and western regions}

In 2017, the average technical efficiency of TCM hospitals in eastern, central and western regions of Hubei Province was $0.891,0.939$ and 0.917 respectively, the average pure technical efficiency was $0.910,0.958$ and 0.939 respectively, and the average scale efficiency was $0.980,0.980$ and 0.977 respectively. The service efficiency of TCM hospitals in central region was better than that in eastern and western regions. Further analysis showed that the average scale efficiency of TCM hospitals in different regions had little difference, and the pure technical efficiency was the main factor leading to the difference of service efficiency in different regions. The economic development in Hubei Province shows the trend of being stronger in the central region and decreasing in the east and west ${ }^{[1]}$. Relatively speaking, TCM hospitals in the central region have a strong economic ability to introduce new equipment and new technology, and are more attractive to high-end talents. On the basis of more high-quality resource input, their service output and efficiency are also better than those in the east and west regions. In order to achieve the goal that everyone can enjoy the service of TCM and improve the fairness of TCM service, special funds should be input in TCM hospitals of underdeveloped areas, and technical assistance and talents cultivation should be carried out with the help of the existing TCM Alliance of Hubei Province, Hubei Provincial Hospital of TCM Group and medical alliances to promote the pure technical efficiency of TCM hospitals in eastern and western regions.

\section{Acknowledgments}

The Project of Consultant and Research of Hubei Research Institute of China Engineering Science and Technology Development Strategy in 2020: Research on the Development Strategy of Traditional Chinese Medicine and the Massive Health Industry in Hubei Province.

\section{References}

1. Ye Chusheng, Xia Shanhua. On Coordinative Development of Hubei Regional Economy [J]. Journal of Hubei University of Economics, 2005(04): 87-92.

2. Farrell M. The Measurement of Productive Efficiency[J]. J Royal StatSoc, 1957, 120(3): 253290.

3. Hollingsworth B, Dawson P, Maniadakis N. Efficiency Measurement of Health Care: A Review of Non-parametric Methods and Applications[J]. Health Care Manag Sci, 1999, 2(3) : 161-172.

4. Guo Shuyan, Li Meng, Dong Siping. Total Factor Productivity and Its Component Changes of 511 Public Secondary General Hospitals in 5 Provinces 
of China [J]. West China Medical Journal, 2019, 34 (12): 1356-1361.

5. Huo Haiying, Wu Weimin. Evaluating the Relative Efficiency of 26 County Hospitals in Guangxi Province Based on Data Envelopment Analysis. [J]. Chinese Health Service Management, 2012, 11: 834-836.

6. Chen Fang, Xiang Yuanwei, Jiang Jianhua, et al. Analyzing the Efficiency of Operation of Guangdong Provincial Traditional Chinese Medicine Hospital and Its Influencing Factors [J]. Chinese Health Service Management, 2018, 10: 744-747.

7. Yuan Lei, Qu Huilong, Lu Xiaojuan, et al. Research on Efficiency of Health Resources Allocation in National Traditional Chinese Medicine Hospitals Based on DEA Model [J]. China Medical Herald, 2019,16 (36): 165-167,177.

8. Bi Jingtao, Wang Zhonghua. Evaluation of Data Envelopment Analysis Efficiency in Tertiary Hospitals in Jiangsu Province [J]. Journal of Nanjing Medical University (Social Sciences), 2018, 3: 230233.

9. Pang Zhenmiao, Zhu Junfeng, Yan Zhilai, et al. Medical Efficiency Study of Traditional Chinese Medicine Service in Guangdong Province Based on DEA Model [J]. Chinese Health Service Management, 2017, 31 (11): 30-33 